\title{
EFFECT OF THE LEG ROTATION CONTROL SPLINT ON ROTATIONAL GAIT PATTERN IN CHILDREN WITH HEMIPLEGIA
} Abd El-Rahman A. Abd El-Hafeez ${ }^{1 *}$; Gehan H. Elmeniawy ${ }^{2}$; Hassan M. Elbarbary ${ }^{3}$ and Amira M. Abd-EIMonem ${ }^{4}$

${ }^{1}$ Master Degree in Physical Therapy for Pediatrics Department, Faculty of Physical Therapy, Cairo University, Egypt.

${ }^{2}$ Professor, Physical Therapy for Pediatrics Department, Dean of Faculty of Physical Therapy, Cairo University, Egypt.

${ }^{3}$ Professor, Orthopedics Department, Faculty of Medicine, Cairo University, Egypt.

${ }^{4}$ Assistant Professor, Physical Therapy for Pediatrics Department, Faculty of Physical Therapy, Cairo University, Egypt.

\section{ABSTRACT}

Background: Rotational deformities of the lower extremities are common in children with cerebral palsy and may lead to abnormal gait pattern. Objective: To determine the effect of leg rotation control splint on outtoeing gait pattern in spastic hemiplegic children. Subjects and methods: Thirty spastic hemiplegic children with out-toeing gait pattern from both genders; age ranged from 24 to 60 months; participated in this study. They were randomly allocated from the Specialized Damietta Hospital, Damietta Governorate. They were divided into two groups of equal numbers (control and intervention). The control group received a designed physiotherapy program based on neurodevelopmental approach for 60 minutes in addition to gait training for 30 minutes while the intervention group received the same physiotherapy program while wearing the leg rotation control splint during the gait training.

Craig's test and foot progression angle were used to measure the femoral ante-version angle and angle of toe out respectively. Each child was measured 2 times, at baseline (pre) and after 3 months (post). Results: The pre-treatment comparison between groups showed non-statistically significant difference in all measured variables.

Regarding the rotational profile parameters, the within group showed nonstatistically significant difference in the trochanteric prominence and foot progression angles. While, there was significant improvement in cadence, speed, step length and stride length while non-statistically significant change was recorded in the step width. Finally, post-treatment comparison showed non-statistically significant difference between the two groups in all measured variables. Conclusion: Physiotherapy program either applied alone or combined with leg rotation control splint improved spatiotemporal gait parameters but didn't change lower limb rotational profile.

Key Words: Cerebral palsy, Hemiplegia, Leg rotation control splint, Rotational gait pattern. 


\section{INTRODUCTION}

The term cerebral palsy (CP) is a neurological condition resulting in different types and levels of impairments. CP may occur at birth where specific parts of the brain have been damaged as a result of a medical complications (Foose and Ardovino, 2008; SwannGuerrero and Mackey, 2008). However, $\mathrm{CP}$ can occur before or right after birth due to, for example, brain haemorrhage, tumor or an injury / trauma that damage the brain. Similarly, as the brain communicates multiple messages to different parts of the body that performs different bodily functions (such as the movement of muscles, the processing of information and coordination), any damage to the brain can result in a range of different impairments depending upon which part of the brain has been effected (Tecklin, 2008; Stanton, 2012; Porretta, 2017).

Spastic hemiplegia, unilateral $\mathrm{CP}$, is a neuromuscular condition of spasticity that results in the muscles on one side of the body being in a constant state of contraction. About 20-30\% of people with CP have spastic hemiplegia. Due to brain or nerve damage, the brain is constantly sending action potentials to the neuromuscular junctions on the affected side of the body. The affected side of the body is rigid, weak and has low functional abilities ( Brashear, 2010).

Gait is a fundamental function that is important for life. Gait is achieved by coordinated movements of body segments, taking advantage of an interaction between internal and external factors, and is accomplished through the action of the neuromusculoskeletal system. Normal gait is both stable and flexible, allowing for changes in speed and maneuvering in different terrains while maintaining energetic efficiency ( Fritz and Lusardi, 2009). Rotational deformities are common lower extremity abnormalities in children with $\mathrm{CP}$, which include in-toeing and out-toeing. In-toeing is caused by one of the three types of deformity: increased femoral anteversion, internal tibial torsion, and metatarsus varus, while out-toeing, the less common form, is caused by femoral retroversion and external tibial torsion. Rotational deformities lead to an ineffective gait pattern since they affect the lever arm of the foot during gait ( Inan et al., 2009).

Different conservative methods were used in treatment of rotational gait profile such as medical shoes, spiral strapping and tapping. However, the effectiveness of these methods on rotational deformities is still debatable. Therefore, the current study aimed to investigate the effect of leg rotation control splint on out-toeing gait pattern in spastic hemiplegic children. We hypothesized that; leg rotation control splint has no effect on out-toeing gait pattern in spastic hemiplegic children.

\section{MATERIALS AND METHODS}

Study design: A randomized trial was conducted from January 2017 to January 2020 at the Outpatient Clinic, Specialized Damietta Hospital, Damietta governorate. 


\section{Ethical approval}

The current study was approved by the ethical committee of the Faculty of Physical Therapy, Cairo University and strictly adhered to the criteria proclaimed in the latest version of the Declaration of Helsinki code of ethics. Additionally, a signed consent form with parents allocated to participate in this study was obtained before starting the study procedures.

\section{Subjects}

Subjects included 30 volunteer children diagnosed as spastic hemiplegic CP. These children were extracted from a dataset of 89 children who are diagnosed with $\mathrm{CP}$ and receive regular physical therapy treatment at Out-patient Clinic, Specialized Damietta Hospital, Damietta Governorate. Children who met the eligible criteria (30 children) were enrolled in the current study and allocated into either control group or intervention group of equal numbers ( 15 children each).

\section{Inclusive criteria:}

1. A diagnosis of spastic hemiplegic $\mathrm{CP}$.

2. Aged from 24 to 60 months.

3 . They did not participate in any previous trials with adhesive tape or spiral strapping to the lower limbs.

4. Grade of spasticity is 1 to 2 (according to modified Ashworth scale) in order to allow the children to be ambulant which in turn made the gait training program convenient for them (Ansari et al., 2008).

5. Level I-II motor function according to GMFCS.

6. Walk with abnormal pattern of gait in the form of out-toeing (according to foot progression angle more than 6.5 degrees), (Thompson, 2003).

7. Able to follow simple commands and instructions.

\section{Exclusive criteria:}

Children were excluded if they had any of the following:

1. Significant visual, auditory or perceptual deficits.

2. Fixed or structural deformities in the lower limb.

3. Surgical interference in the lower limb in the past 6 months.

4. Uncontrolled seizures or epilepsy.

5. Botox injection in past 6 months in the lower limbs.

6 . Fracture of the lower limb in the past 6 months.

\section{Randomization:}

A person not otherwise involved in the trial randomly allocated participant, to the control or intervention group using closed envelops.

Control group: The 15 children in this group received a designed physical therapy program based on neurodevelopmental approach (NDT) for 60 minutes in addition to gait training for 30 minutes.

Intervention group: The 15 children in this group received the same designed physical therapy program given to the control group while wearing the leg rotation control splint during the gait training. 
The treatment was conducted 3 days/week for 12 successive weeks for the two groups. Children in both groups received a home based routine program for 90 minutes per day in the other three days of the week giving one day rest.

Materials:

I- Materials for subject selection:

The following instruments were used for subject selection according to the inclusive criteria:

\section{1- Modified Ashworth scale}

It was used to assess the degree of spasticity. It is frequently used to evaluate the muscle tone changes during passive stretch to the investigated muscles through the full ROM. It is based on six point ordinal scale $(0,1,1+, 2,3,4)$ with normal muscle tone referred as zero, whereas a score of 4 is assigned for severe spasticity with no motion is possible (Ansari et al., 2008).

\section{2- Foot progression angle}

The foot progression angle (FPA) was used to determine the degree of angle of toe-out. It is defined as the angle between the line from the calcaneous to the second metatarsal and the line of progression averaged from heel strike to toe off during the stance phase of walking for each step ( Xu et al., 2017).

\section{3- Gross motor function classification system}

The GMFCS was used to determine the level of motor function based on functional and walking abilities in children with $\mathrm{CP}$ and on their chronological age. The scale classify children intone of five levels according to their functional abilities. Children with GMFCS level I can walk without Limitations, whereas those with level V have severe head and trunk control limitations and require physical assistance. The current study included children with level I-II (Palisano et al., 2007).

\section{II-Materials for assessment:}

1- Weight and height scales: The Hanson professional scale was used to measure the weight and height.

\section{2- Foot progression angle and spatial gait parameters:}

The FPA was measured by obtaining foot print while the child walked at regular self-speed with bare feet. Gait analysis using footprint impressions is a simple and inexpensive method of obtaining valuable information relating to foot dynamics. Powdered footprint is a reliable and repeatable method for measuring FPA, step length and step width (Taranto et al., 2005).

\section{3- Temporal gait parameters:}

A stop watch was used to determine the walking speed and cadence while the child was asked to walk on a five meters walk way.

\section{4- Craig's test:}

This test is known as hip rotation range of motion (ROM) (Sangeux , et al., 2014) . It was used to determine the trochanteric prominence angle (TPA) using goniometer. Hip rotation ROM may be an appropriate clinical 
measure to estimate $\mathrm{FV}$, as it is commonly performed during clinical examination, has good reliability and is associated with FV (Ejnisman, et al., 2013) . Increased FV values are associated with decreased hip external rotation and increased internal rotation ROM, while decreased FV may contribute to decreased internal rotation ROM increased external rotation ROM ( Uding et al., 2019). Chung et al., (2010) reported Craig's test as being both accurate and valid for determining femoral version (FV) compared to CT. He also found high correlations between Craig's test and $\mathrm{CT}$ values in children with $\mathrm{CP}$.

\section{III-Materials for treatment:}

\section{- Physical therapy tools}

The following therapeutic tools were used to conduct the designed physical therapy program for the two groups including gymnastic balls, wedges, rolls, tilting boards of different sizes and mattresses, in addition to stepper, wall bar, stand bar and large mirror for gait training.

- The leg rotation control splint:

It was used aiming to correct the out-toeing gait pattern in the intervention group (Figure 1).

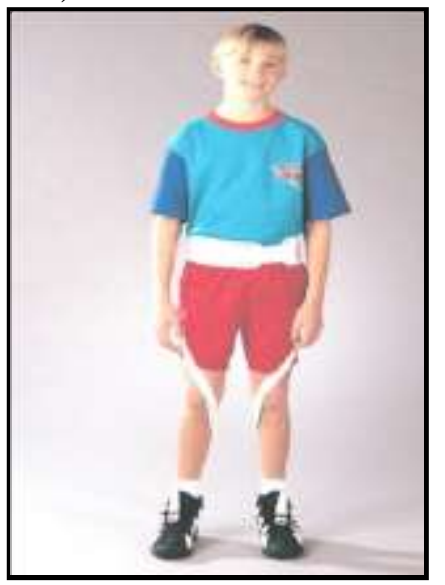

Figure (1): The leg rotation control splint

1). It is a commercially available splint that is frequently used in children with abnormal lower limb rotational profile e.g. CP (available at 2020 from www.performancehealth.ca/leg-rotation-control). The splint consists of:

1- Pelvic belt.

2- Shoe hooks.

3- An elastic spiral strap that is attached to the shoe hook and extend on the affected limb (spiral) up to the pelvic belt. The strap serves as a counter rotation force that allows maintaining the foot in neutral position and decreases of the leg (out-toeing). 
4- Two elastic straps connected to the pelvic belt posteriorly (directed upward) and turn above the shoulder girdles to be connected anteriorly again in the belt, these straps guard against the downward slippage of the belt due to the equinus foot (optional).

Methods:

The child's name, weight, sex, affected side; height and age for each child were recorded before preceding the study procedures.

\section{I- Methods for assessment}

\section{- Foot progression angle and spatiotemporal gait parameters}

Footprint data were obtained using white paper sheet $[5$ meters $(\mathrm{m})$ length, 100 centimeter $(\mathrm{cm})$ width]. The sheet was put over an elevated walkway of $5 \mathrm{~m}$ length. The child's feet were placed in a container of red colored powder and gently shaken off to remove any excess powder. The child was instructed to walk normally to the other end, looking straight ahead, commencing with the affected foot. For accuracy, the first two steps were excluded from measurement. Marker pen, a stainless steel ruler, a transparent plastic protractor and a transparent grid, made up of parallel lines was used to measure lengths and angles (see figure 2). The longitudinal border of the grid was aligned with the apex of the hallux and the medial side of the forefoot. To ensure parallel placement of the grid, the distance between the top and bottom margins of the grid and the border of the paper were measured. The grid was used to draw 2 lines parallel to each other representing the apex of the hallux and at the posterior aspect of the heel. The longitudinal border of the grid adjacent to the medial side of the forefoot was marked at either end. The grid was removed and the two points joined to formulate the line of progression (LOP). The intersection between LOP and the foot axis (line intersecting the center of the heel and the second toe) constructs FPA. Spatiotemporal parameters [stride length in $\mathrm{cm}$, step length in $\mathrm{cm}$, step width in $\mathrm{cm}$, cadence in steps/minute, and speed in kilometers/hour $(\mathrm{km} / \mathrm{h})]$ were measured by using foot print ( Taranto et al., 2005).

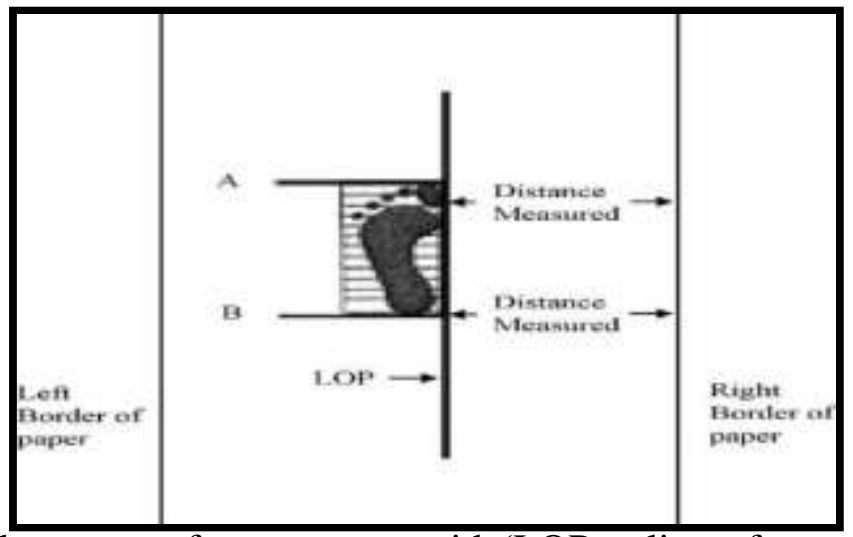

Figure (2): Placement of transparent grid (LOP = line of progression). Adopted from ( Taranto et al., 2005) 


\section{- Trochanteric prominence angle}

Femoral ante-version is described as the angular difference between the axis of the femoral neck and trans-condylar axis of the femur or simply torsion of the femur. Measurement of ante-version by physical examination is done with the child in the prone position, measuring internal and external rotation of the hip, and making sure there is no rotation of the pelvis. The degree of internal rotation is measured as the angle subtended by the tibia to the vertical line (See figure 3).

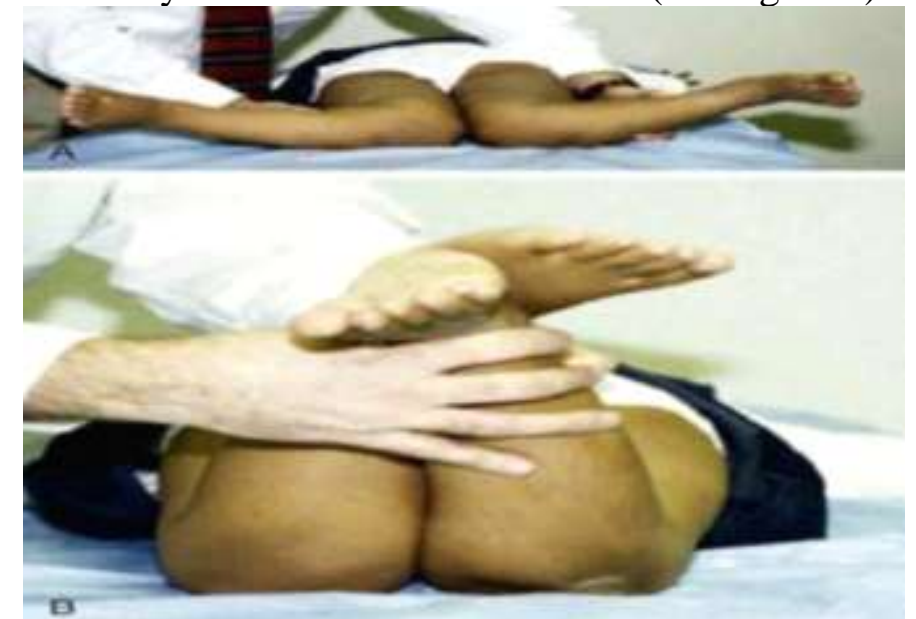

Figure (3): (A) Anteversion measured by medial rotation of hip and ( B) lateral rotation of hip ( Wells, 2004).

\section{II- Methods for treatment:}

The two groups received the same designed physical therapy program while children in the intervention group performed the program while using the leg rotation control splint during the gait training. The splint should be worn from down upwards, the elastic strap should not be slack and should rotate two rotations around the lower limb one of them in the popliteal fossa and the other posteriorly to be attached to the pelvic belt. The program includes:

- Neurodevelopmental approach which was directed towards inhibiting abnormal muscle tone and abnormal postural reflexes and facilitation of normal movement patterns of postural control through reflex inhibiting positions using proximal and distal key points of control.

- Facilitation of righting, equilibrium and protective reactions to improve postural mechanisms via variety of exercises applied on balance board through tilting from different positions in forward, backward and sideways.

- Stretching exercises to maintain the length and the elastic properties of the muscles which are liable for shortening especially Achilles tendon, hamstrings, hip flexors and adductors of the affected lower limb while in the 
upper limb the shoulder internal rotators, elbow and wrist flexors, pronators and ulnar deviators.

- Hand weight bearing and stretching exercises to improve the hand function, also facilitation of reaching, grasping and release according to the child abilities.

- Gait training activities including:

- Sideway, forward and backward walking training in front of a large mirror using stepper.

- Training of walking in open environment by placing obstacles across walking tract as rolls of different diameters and wedges of different heights.

- Training of walking on different floor surfaces (Spongy, sandy and hard surfaces) on mat, on the floor and on the carpets ( Levitt, 2004).

\section{RESULTS}

\section{I- General characteristics of the study groups:}

Table (1) shows the general characteristics of the study groups. The mean age, weight, and height as well as, the frequency distribution of gender and affected limb showed non-statistically significant difference between the study groups $(\mathrm{p}<0.05)$.

Table (1): Analysis of the general characteristics of the study groups

\begin{tabular}{|c|c|c|c|c|c|c|c|}
\hline \multicolumn{2}{|c|}{ Item } & \multicolumn{2}{|c|}{ Control group } & \multicolumn{2}{|c|}{ Intervention group } & Test of sig & P-value \\
\hline \multirow[t]{2}{*}{ Gender N/(\%) } & Boy & 8 & $53.3 \%$ & 5 & $33.3 \%$ & \multirow[t]{2}{*}{$x^{2}=1.222$} & \multirow[t]{2}{*}{0.269} \\
\hline & Girl & 7 & $46.7 \%$ & 10 & $66.7 \%$ & & \\
\hline \multirow[t]{2}{*}{ Affected side } & Right & 4 & $26.7 \%$ & 9 & $60 \%$ & \multirow[t]{2}{*}{$X^{2}=3.394$} & \multirow[t]{2}{*}{0.065} \\
\hline & Left & 11 & $73.3 \%$ & 6 & $40 \%$ & & \\
\hline \multicolumn{2}{|c|}{ Age (months) $\bar{X}$} & \multicolumn{2}{|c|}{$41.27 \pm 12.09$} & \multicolumn{2}{|c|}{$42.71 \pm 12.63$} & $\mathbf{t}=\mathbf{0 . 3 1 7}$ & 0.753 \\
\hline \multicolumn{2}{|c|}{ Height $(\mathrm{cm})$} & \multicolumn{2}{|c|}{$96.51 \pm 7.34$} & \multicolumn{2}{|c|}{$96.23 \pm 10.54$} & $t=-0.081$ & 0.936 \\
\hline Weight & $\overline{\mathrm{X}}_{ \pm \mathrm{SD}}$ & \multicolumn{2}{|c|}{$14.97 \pm 2.15$} & \multicolumn{2}{|c|}{$14.76 \pm 3.22$} & $\mathrm{t}=-\mathbf{0 . 2 0 8}$ & 0.837 \\
\hline
\end{tabular}

$\bar{X}$ SD: Standard deviation probability value $\mathrm{T}$ : $\mathrm{t}$-test $:$ mean

$(\%)$ : percentage $X 2$ : Chi-square test $P$-value:

\section{II- Pretreatment comparison of the study groups:}

The pretreatment comparison of lower limb rotational profile parameters and spatiotemporal gait parameters are determined in (Table 2 ). The results showed non-statistically significant difference between the two groups regarding FPA, TPA, cadence, speed, step length, stride length and, step width $(\mathrm{p}<0.05)$. 
Table (2): Pre-treatment comparison of lower limb rotational profile and spatiotemporal parameters in the two groups:

\begin{tabular}{|l|c|c|c|c|}
\hline \multicolumn{1}{|c|}{ Item } & Control group & Intervention group & Test of sig & P-value \\
\hline Foot progression angle (degree) & $27(12-45)$ & $26(12-51.3)$ & $\mathrm{z}=-\mathbf{0 . 0 6 2}$ & 0.637 \\
\hline $\begin{array}{l}\text { Trochanteric prominence angle } \\
\text { (degree) }\end{array}$ & $35.73 \pm 2.72$ & $35.87 \pm 2.05$ & $\mathrm{t}=-\mathbf{0 . 1 5 2}$ & $\mathbf{0 . 8 8 0}$ \\
\hline Cadence (Step/min) & $98.13 \pm 22.70$ & $97.80 \pm 24.32$ & $\mathrm{t}=\mathbf{0 . 0 3 9}$ & $\mathbf{0 . 9 6 9}$ \\
\hline Speed $(\mathrm{Km} / \mathrm{h})$ & $1.7(0.85-3.40)$ & $1.62(0.72-4.28)$ & $\mathrm{z}=-\mathbf{0 . 4 1 5}$ & $\mathbf{0 . 6 7 8}$ \\
\hline
\end{tabular}

$\overline{\mathrm{X}}$

\begin{tabular}{|l|l|r|r|r|}
\hline Step length $(\mathrm{Cm})$ & \multicolumn{1}{|c|}{$40.08 \pm 6.77$} & $41.27 \pm 12.43$ & $\mathbf{t}=\mathbf{0 . 3 6 2}$ & $\mathbf{0 . 7 7 4}$ \\
\hline Stride length $(\mathrm{Cm})$ & $\mathbf{6 5 . 1 2} \pm \mathbf{1 1 . 2 1}$ & $\mathbf{6 9 . 0 2} \pm 23.14$ & $\mathbf{t}=\mathbf{0 . 5 8 7}$ & $\mathbf{0 . 5 6 2}$ \\
\hline Step width $(\mathrm{Cm})$ & $\mathbf{2 4 . 4 5} \pm 4.93$ & $\mathbf{2 4 . 3 5} \pm 4.83$ & $\mathbf{t}=\mathbf{0 . 0 5 6}$ & $\mathbf{0 . 9 5 6}$ \\
\hline
\end{tabular}

T: t-test SD: Standard deviation P-value: probability value Z: Mann-Whitney test $(\%)$ : percentage : mean

III-Pre and post-treatment comparison of the control group

The pre and post treatment comparison of the rotational profile parameters (FPA, TPA) and step width shows no statistically significant difference $(p<0.05)$, while the spatiotemporal gait parameters (step length, stride length, cadence, speed) show statistically significant difference as demonstrated in (Table 3) ( $p>0.05$ ).

Table (3): Pre and post treatment comparison of lower limb rotational profile and spatiotemporal gait parameters of the control group

\begin{tabular}{|c|c|c|c|c|}
\hline \multirow{2}{*}{ Item } & \multicolumn{2}{|c|}{ Control group } & \multirow{2}{*}{ Test of sig } & \multirow{2}{*}{ P-value } \\
\hline & Pre-treatment & Post-treatment & & \\
\hline Foot progression angle (degree) & $27(12-45)$ & $30(12-46)$ & $z=-0.059$ & 0.956 \\
\hline $\begin{array}{l}\text { Trochanteric prominence angle } \\
\text { (degree) }\end{array}$ & $35.73 \pm 2.72$ & $35.67 \pm 3.04$ & $\mathrm{t}=\mathbf{0 . 1 3 3}$ & 0.896 \\
\hline Cadence (Step/min) & $98.13 \pm 22.70$ & $113.13 \pm 22.70$ & $t=-7.061$ & $<0.001 *$ \\
\hline Speed $(\mathbf{K m} / \mathbf{h})$ & $1.7(0.85-3.40)$ & $3(2-6.1)$ & $z=-2.670$ & 0.008* \\
\hline Step length $(\mathrm{Cm})$ & $40.08 \pm 6.77$ & $61.11 \pm 6.43$ & $t=-24.344$ & $<0.001 *$ \\
\hline Stride length $(\mathbf{C m})$ & $65.12 \pm 11.21$ & $105.12 \pm 13.39$ & $t=-31.813$ & $<0.001 *$ \\
\hline Step width $(\mathbf{C m})$ & $24.45 \pm 4.93$ & $24.59 \pm 5.74$ & $t=-0.351$ & 0.731 \\
\hline
\end{tabular}

\section{IV-Pre and post-treatment comparison of the intervention group}

The pre and post treatment comparison of the rotational profile parameters (FPA, TPA) and step width shows no statistically significant difference $(\mathrm{p}<0.05)$, while the spatiotemporal gait parameters (step length, stride length, cadence, speed) show statistically significant difference as demonstrated in (Table 4) ( $p>0.05)$. 
Table (4): Pre and post treatment comparison of lower limb rotational profile and spatiotemporal gait parameters of the intervention group

\begin{tabular}{|c|c|c|c|c|}
\hline \multirow[t]{2}{*}{ Item } & \multicolumn{2}{|c|}{ Intervention group } & \multirow[t]{2}{*}{ Test of sig } & \multirow[t]{2}{*}{ P-value } \\
\hline & Pre-treatment & Post-treatment & & \\
\hline Foot progression angle (degree) & $26(12-51.3)$ & $29(13-52)$ & $\mathrm{z}=-\mathbf{0 . 2 6 8}$ & 0.789 \\
\hline $\begin{array}{l}\text { Trochanteric prominence angle } \\
\text { (degree) }\end{array}$ & $35.87 \pm 2.05$ & $35.93 \pm 2.70$ & $\mathrm{t}=-\mathbf{0 . 1 3 5}$ & 0.894 \\
\hline Cadence (Step/min) & $97.80 \pm 24.32$ & $117.80 \pm 24.32$ & $\mathrm{t}=-\mathbf{5 . 7 2 7}$ & $<0.001 *$ \\
\hline Speed $(\mathrm{Km} / \mathbf{h})$ & $1.62(0.72-4.28)$ & $3.2(1.9-6.1)$ & $\mathrm{z}=-\mathbf{3 . 4 0 8}$ & 0.001* \\
\hline Step length $(\mathrm{Cm})$ & $41.27 \pm 12.43$ & $63.09 \pm 21.81$ & $t=-6.510$ & $<0.001 *$ \\
\hline Stride length $(\mathrm{Cm})$ & $69.02 \pm 23.14$ & $110 \pm 38.84$ & $\mathrm{t}=-\mathbf{7 . 4 5 7}$ & $<0.001 *$ \\
\hline Step width $(\mathbf{C m})$ & $24.35 \pm 4.83$ & $24.42 \pm 5.14$ & $t=-0.201$ & 0.845 \\
\hline
\end{tabular}

- T: t-test SD: Standard deviation P-value: probability value $\quad Z$ : Mann-Whitney test : mean

\section{V- Post-treatment comparison of the study groups:}

The post-treatment comparison of lower limb rotational profile parameters and spatiotemporal gait parameters are determined in (Table $5)$. The results showed non-statistically significant difference between the two groups regarding FPA, TPA, cadence, speed, step length, stride length and, step width ( $\mathrm{p}<0.05)$.

Table (5): Post-treatment comparison of lower limb rotational profile and spatiotemporal parameters in the two groups:

\begin{tabular}{|l|c|c|c|c|}
\hline \multicolumn{1}{|c|}{ Item } & Control group & Group intervention & Test of sig & P-value \\
\hline Foot progression angle (degree) & $30(12-46)$ & $29(13-52)$ & $\mathrm{z}=-\mathbf{0 . 1 4 5}$ & $\mathbf{0 . 9 0 2}$ \\
\hline $\begin{array}{l}\text { Trochanteric prominence angle } \\
\text { (degree) }\end{array}$ & $35.67 \pm 3.04$ & $35.93 \pm 2.70$ & $\mathrm{t}=-\mathbf{0 . 2 5 4}$ & $\mathbf{0 . 8 0 1}$ \\
\hline Cadence $($ Step/min) & $113.13 \pm 22.70$ & $117.80 \pm 24.32$ & $\mathrm{t}=-\mathbf{0 . 5 3 4}$ & $\mathbf{0 . 5 9 1}$ \\
\hline Speed $(\mathrm{Km} / \mathbf{h})$ & $3(2-6.1)$ & $3.2(1.9-6.1)$ & $\mathrm{z}=-\mathbf{0 . 2 0 8}$ & $\mathbf{0 . 8 3 8}$ \\
\hline Step length $(\mathbf{C m})$ & $61.11 \pm 6.43$ & $\mathbf{6 3 . 0 9} \pm \mathbf{2 1 . 8 1}$ & $\mathrm{t}=-\mathbf{0 . 3 3 7}$ & $\mathbf{0 . 7 3 8}$ \\
\hline Stride length $(\mathbf{C m})$ & $105.12 \pm 13.39$ & $110 \pm 38.84$ & $\mathrm{t}=-\mathbf{0 . 4 6 0}$ & $\mathbf{0 . 6 4 9}$ \\
\hline Step width $(\mathbf{C m})$ & $24.59 \pm 5.74$ & $24.42 \pm 5.14$ & $\mathrm{t}=\mathbf{0 . 0 8 4}$ & $\mathbf{0 . 9 3 4}$ \\
\hline
\end{tabular}

$\mathrm{X}_{\mathrm{T}}$ : t-test SD: Standard deviation $\mathrm{P}$-value: probability value $\mathrm{Z}$ : Mann-Whitney test : mean

\section{DISCUSSION}

This study was conducted to investigate the effect of the leg rotation control splint on the rotational gait pattern in hemiplegic children. We hypothesized that; leg rotation control splint has no effect in improving the rotational gait pattern in children with hemiplegia. For this purpose, thirty hemiplegic children were allocated from the Specialized Damietta Hospital, Damietta Governorate. Both sexes were involved with age ranged from 24 to 60 
months. Subjects were divided into two groups of equal number (control and intervention), 15 children in each group.

The main outcomes of the current study revealed within group and between groups non-statistically significant difference of FPA and TPA mean values. While there was significant improvement of cadence, speed, step length and stride length in the two groups with non-statistically significant difference regarding the step width. However, post-treatment comparison between the two groups showed non-statistically significant difference in respect with cadence, speed, step length, stride length and the step width.

The current study included children with hemiplegic $\mathrm{CP}$ with out-toeing gait profile. This selection was accredited to the fact that, children with hemiplegic CP have a wide variety of gait deviations related to the abnormal tone, lack of selective motor control and musculoskeletal disorders. Consequently, those children have lower limb rotational abnormalities and abnormal spatio-temporal parameters when compared with typically developing age matched children. This is supported by previous studies documented that, children with spastic hemiplegic $\mathrm{CP}$ exhibit several musculoskeletal abnormalities of the lower extremities that result in gait and balance disorders. In a child with spastic $\mathrm{CP}$, the relationships between the different symptoms of the upper motor neuron lesions; weakness, spasticity, co-activation, loss of movement selectivity; and gait parameters or effective performance remain debatable. The abnormal gait patterns among this population are a mixture of primary (disordered motor control) and secondary (musculo-skeletal deformities (Gage et al., 2009; Stebbins et al., 2010; Kedem and Scher, 2015; Gross et al., 2015). Sikina et al., (2012) documented that, the gait pattern of the paretic and non-paretic sides of hemiparetic children are different compared to healthy subjects. They show shorter stance phase; significantly reduced velocity, stride length, step length and cadence compared to healthy subjects. However step width is increased considerably.

The age of children representing the sample of this study ranged from 24 to 60 months with the mean value of $42.71 \pm 12.63$ months for the intervention group and 41.27 12.09 months for the control group. The selected age was based on the fact that, the development of lower limb rotational profile is achieved in infancy and early childhood through weight bearing activities such as walking. This is supported with Schoenecker et al., (2014) who reported that, in-toeing and out-toeing may be accentuated between six months and five years of age, when children are developing their walking and coordination skills. Normal growth and improved coordination typically lead to spontaneous resolution of rotational variations.

The non-significant changes recorded in FPA and TPA can be attributed to the ineffectiveness use of leg rotation control splint which intended to achieve improvement in FPA and TPA. This could be attributed to type of splint used in the current study which is a commercially available splint that can be easily obtained and applied. The authors noticed that, parents preferred this type of splint as it is light in weight, can be worn under the child clothes and easily 
applied. However, the degree of tension of the elastic rope of the splint is variable as the elasticity changes after time and is subjectively adjusted to maintain the foot in appropriate position. Moreover, it is comfortable and does not cause tension on the soft tissues therefore children did not show any rejection regarding the orthosis.

This is confirmed by Staheli, (2008) who reported that, bracing and twister cables are ineffective in correcting the version of the femur. Derotational osteotomy may be indicated in patients with hip pain, severe gait disturbance, or cosmetic deformity. Our results are consistent with Schoenecker et al., (2006) who concluded that, non-operative interventions (e.g., shoe inserts, braces, twister cables, casting) are ineffective in the treatment of internal and external tibial torsion and increased femoral ante-version and femoral retroversion.

This comes in agreement with Behnam et al., (2007) who reported that, out-toeing is less common than in-toeing, and its causes are similar but opposite to those of in-toeing. In most cases, the abnormality improves with time. A careful physical examination, explanation of the natural history, and serial measurements are usually reassuring to the parents. Treatment is usually conservative. Special shoes, cast, or braces are rarely beneficial and have no proven efficacy. Surgery is reserved for older children with deformity from three to four standard deviations from the normal.

The results can be also attributed to the concept that, the leg rotation control does not provide proprioceptive feedback unlike other orthosis and Kinesio tape. This comes in line with Öhman, (2013) who stated that, the tape provides proprioceptive feedback to achieve and maintain preferred body alignment. It is a complementary treatment and is designed to facilitate the body's natural healing process while allowing support and stability to muscles and joints without restricting the body's range of motion.

The results of the current study also revealed significant improvement in spatio-temporal gait parameters in both the control and intervention group. This could be attributed the NDT based physical therapy program and gait training which intended to inhibit hypertonicity of the muscles, improve motor control, increase strength and muscle endurance, facilitate gross motor performance and improve balance as well as gait. This comes in agreement with previous studies stated that, functional gait training in children with $\mathrm{CP}$ allows for repetition of motor task to drive skill acquisition. Targeting improved walking ability, with training, may lead to gains in increased independence and follow with increased participation in daily life (French et al., 2010; Langhorne et al., 2011).

Herskind et al., (2016) conducted a pilot study to investigate the effects of intensive gait training in toddlers with CP. The gait training was conducted for one hour/day, five days/week for three consecutive months. This pilot study suggests that intensive gait training may increase muscle volume, improve walking skills and reduce passive muscle stiffness in toddlers with CP.

Functional gait training allows for repetition of motor task to drive skill acquisition. It can be defined as actively practicing the task of walking, to improve walking ability ( Langhorne et al., 2011; Yang et al., 2013). 
It has been reported that, the use of NDT for children with CP improved motor skills functionality. It may be that, NDT treatment effects are obvious in the postural control used for gross motor performance and caused improved functional ability ( Labaf et al., 2015).

The results can be also attributed to potential benefits of NDT and gait training program applied in a critical age of this study sample. This is supported with who stated that, it is crucial to ensure development of the motor skills required for children with $\mathrm{CP}$ to become physically active early in life to avoid atrophy and loss of function (Herskind et al., (2016). Similarly, previous studies reported that, the young brain appears to be more plastic and thus more susceptible to intervention than the adult brain (Friel et al., 2012; Herskind et al., 2015). Furthermore, Yang et al., (2013) suggested that gait training in toddlers with an early brain lesion may positively affect functional ability and cause plastic changes in the corticospinal pathway.

The improvement recorded in the two groups can be attributed to the duration and frequency of the treatment. The statistical analysis revealed significant improvements in all measured variables after treatment in both groups as the main effect of time was statistically significant. The two groups received a treatment program which was conducted for 90 minutes three-times a week for three successive months in addition to home routine program in the other three days giving one day rest per week, which is considered as an intensive program. Trahan and Malouin, (2002) and Tsorlakis et al., (2004) stated that increasing the frequency and duration of therapy sessions may produce significant and long-lasting changes in strength, tone, posture and gross motor performance; however, the success of any therapy depends on the commitment of the parents, caregivers, child and therapists. Polovina et al., (2010) reported that, intensive treatment was found to have a greater effect than non-intensive one. A treatment was defined to be intensive if it was undertaken for more than three times per week.

Similarly, a recent randomized controlled study conducted by Park, (2016) who investigated the effect of physical therapy frequency based on NDT on gross motor function in children with $\mathrm{CP}$ concluded that intensive physical therapy is more effective for improving gross motor function in children with $\mathrm{CP}$. In particular, crawling and kneeling, and standing ability showed greater increases with intensive physical therapy.

\section{Limitations}

Overall, our study supports the hypothesis that leg rotation control splint has no effect on improving the rotational gait pattern in children with hemiplegia. However, this study is not exempt of limitations. The major limitations of the current study were lack of reevaluation and follow-up after completion of the intervention. Another limitation was that, the selected sample had out-toe gait pattern which is less common than in-toeing therefore the sample size was relatively small to generalize the results. Finally, the body mass index was not estimated which is essential indicator for weight control among children with disabilities. These potential sources of bias should be controlled in 
future studies to provide a better understanding and overview about the role of conservative orthotic management of lower limb abnormal rotational profile in children with CP.

\section{Acknowledgements}

We would like to express our sincere appreciation to all physiotherapists and nurses working at the Out-patient Clinic, Specialized Damietta Hospital, Damietta Governorate who participated in the study procedures. The authors cannot forget to thank all children and their parents, for their collaboration in this study.

\section{Declaration of conflicting interests}

The authors declared no potential conflicts of interest with respect to the research, authorship, and/or publication of this work.

\section{Funding}

The authors received no financial support for the research, authorship, and/or publication of this article.

\section{REFERENCES}

Ansari, N.N. ; S. Naghdi ; T.K. Arab and et al. (2008). "The interrater and intrarater reliability of the Modified Ashworth Scale in the assessment of muscle spasticity: limb and muscle group effect". NeuroRehabilitation., 23 (3): 231-237.

Brashear, A. (2010). Spasticity: Diagnosis and Management. New York: Demos Medical.

Chung, C.Y. ; K.M. Lee ; M.S. Park and et al. (2010). Validity and reliability of measuring femoral anteversion and neck-shaft angle in patients with cerebral palsy. JBJS, 92(5): 1195-1205.

Ejnisman, L. ; M.J. Philippon ; P. Lertwanich and et al. (2013). Relationship between femoral anteversion and findings in hips with femoroacetabular impingement. Orthopedics.,36:293-300.

Foose, A. and P. Ardovino (2008). Therapeutic Recreation and Developmental Disabilities. In: Robertson, T. and Long, T., eds. Foundations of Therapeutic Recreation: perceptions, philosophies and practices for the 21st century. Champaign, IL: Human Kinetics, 127-144.

French, B. ; L. Thomas ; M. Leathley and et al. (2010). Does repetitive task training improve functional activity after stroke? A Cochrane systematic review and meta-analysis. J Rehabil Med; 42: 9-14.

Friel, K. ; S. Chakrabarty ; H.C. Kuo and et al. (2012). Using motor behavior during an early critical period to restore skilled limb movement after damage to the corticospinal system during development. J Neurosci; 32(27):9265-76.

Fritz, S. and M. Lusardi (2009). White paper: "walking speed: the sixth vital sign". J. Geriatr Phys Ther., 32: 46-49. 
Gage, J. ; M. Schwartz ; S. Koop and T. Novacheck (2009): The identification and treatment of gait problems in cerebral palsy. 2nd edition. Mac Keith Press, London,p 34.

Gross, R. ; F. Leboeuf ; N.J. Hardoui and et al. (2015): Does muscle coactivation influence joint excursions during gait in children with and without hemiplegic cerebral palsy? Relationship between muscle coactivation and joint kinematics. Clinical Biomechanics. Dec; 30(10):1088-1093.

Gulan, G. ; D. Matovinović ; B. Nemec and et al. (2000). Femoral neck antever Values, development, measurement,common problems. Collegium Antropologicum, 24(2): 521-527.

Herskind, A. ; G. Greisen and J.B. Nielsen (2015). Early identification and intervention in cerebral palsy. Dev Med Child Neurol; 57(1):29-36.

Herskind, A. ; M. Willerslev-Olsen ; A. Ritterband-Rosenbaum and et al. (2016). Intensive gait training in toddlers with cerebral palsy: A pilot study. Adv Pediatr Res., 3:8. doi:10.12715/apr.2016.3.8

Inan, M. ; F. Altintaş and I. Duru (2009). 'The evaluation and management of rotational deformity in cerebral palsy', Acta Orthopaedica et Traumatologica Turcica, 43(2): 106-112.

Kedem, P. and D. Scher (2015): Foot deformities in children with cerebral palsy. Journal of Current opinion in pediatrics; 27(1):67-74.

Labaf, S. ; A. Shamsoddini and A. Shakibaee (2015). Effects of Neurodevelopmental Therapy on Gross Motor Function in Children with Cerebral Palsy. Iran J Child Neurol ;9 (2): 36-41.

Langhorne, P. ; J. Bernhardt and G. Kwakkel (2011): Stroke rehabilitation. Lancet; 377 (12): 1693-1702.

Levitt, S. (2004). Treatment of cerebral palsy and motor delay, 2nd ed. Black well scientific publisher, London.

Mooney, J.F. (2014). Lower extremity rotational and angular issues in children. Pediatr Clin North Am.; 61(6):1175-1183.

Öhman, A.M. (2013). Kinesiology Taping a Therapeutic Tool in the Paediatric Population? J Nov Physiother 3:5 http://dx.doi.org/10.4172/21657025.1000173

Palisano, R. ; P. Rosenbaum ; D. Bartlett and et al. (2007). Gross Motor Function Classification System Expanded and Revised. Reference: Dev Med Child Neurol, 39, 214-223. https://doi.org/10.1111/j.14698749.2. Reference: Dev Med Child Neurol, 39, 214-223.

Park, E. (2016). Effect of physical therapy frequency on gross motor function in children with cerebral palsy. J. Phys. Ther. Sci., 28: 1888-1891. 
Polovina, S. ; T. Sâkoric ; P. Andrea and et al. (2010). Intensive Rehabilitation in Children with Cerebral Palsy: Our View on the Neuronal Group Selection Theory. Coll. Antropol., 34 (3): 981-988.

Porretta, D.L. (2017). Cerebral Palsy, Traumatic Brain Injury, and Stroke. In: Winnick, J P and Porretta, D L., eds. Adapted Physical Education and Sport. 6 th ed. Champaign, IL: Human Kinetics, 217-290.

Sangeux, M. ; J. Mahy and H.K. Graham (2014). Do physical examination and ctscan measures of femoral neck anteversion and tibial torsion relate to each other? Gait Posture., 39:12-16.

Schoenecker, P.L. and M.M. Rich (2006). The lower extremity. In: Lovell and Winter's Pediatric Orthopaedics, 6th ed, Morrissy RT, Weinstein SL (Eds), Lippincott Williams \& Wilkins, Philadelphia., p.1158.

Schoenecker, P.L. ; M.M. Rich and J.E. Gordon (2014). The lower extremity. In: Lovell and Winter's Pediatric Orthopaedics, 7th ed, Weinstein SL, Flynn JM (Eds), Wolters Kluwer Health, Philadelphia., p.1261.

Sikina, A. ; N. Xiao ; Y. Chen and et al. (2012). Spatiotemporal and Joint Kinematic Analyses in Hemiparetic Cerebral Palsy Children During Stance Phase.

Staheli, L.T. (2008). Lower limb. In: Fundamentals of Pediatric Orthopedics, 4th ed, Lippincott Williams \& Wilkins, Philadelphia., p.135.

Stanton, M. (2012). Understanding Cerebral Palsy: A Guide for Parents and Professionals. London: Jessica Kingsley Publishers.

Stebbins, J. ; N.M. Harringto ; N. Thompson and et al. (2010): Gait compensations caused by foot deformity in cerebral palsy. Gait Posture; 32(2):226-230.

Swann-Guerrero, S. and C. Mackey (2008). Wellness through Physical Activity. In: Robertson, T. and Long, T., eds. Foundations of Therapeutic Recreation: perceptions, philosophies and practices for the 21st century. Champaign, IL: Human Kinetics, 199-216.

Taranto J, Taranto M J, Bryant A et al. (2005). Angle of gait: A comparative reliability study using footprints and the EMED-SF®. Foot, 15(1): 713.

Tecklin, J.S. (2008). Pediatric Physical Therapy. 4 th ed. London: Lippincott Williams \& Wilkins

Thompson, G.H. (2003). Gait disturbances. In: Kliegman RM, ed. Practical strategies in pediatric diagnosis and therapy, ed 2. Philadelphia: WB Saunders; 823-843.

Trahan, J. and F. Malouin (2002). Intermittent intensive physiotherapy in children with cerebral palsy: a pilot study. Dev Med Child Neurol.; 44:233-9. 
Tsorlakis, N. ; C. Evaggelinou ; G. Grouios and et al. (2004). Effect of intensive neurodevelopmental treatment in gross motor function of children with cerebral palsy. Dev Med Child Neurol; 46:740-745.

Uding, A. ; N.J. Bloom and P.K. Commean (2019). Clinical tests to determine femoral version category in people with chronic hip joint pain and asymptomatic controls. Musculoskeletal science \& practice, 39: $115-122$.

Wells L. (2004). / Evaluation / Foot Progression Angle Femoral Anteversion / Evaluation / Foot Progression Angle Tibial Rotation.

Xu, J. ; T. Bao ; U.H. Lee and et al. (2017). Configurable, wearable sensing and vibrotactile feedback system for real-time postural balance and gait training: Proof-of-concept. Journal of NeuroEngineering and Rehabilitation. 14. 10.1186/s12984-017-0313-3.

Yang, J.F. ; D. Livingstone ; K. Brunton and et al. (2013). Training to enhance walking in children with cerebral palsy: are we missing the window of opportunity? Semin Pediatr Neuro., 20(2):106-15.

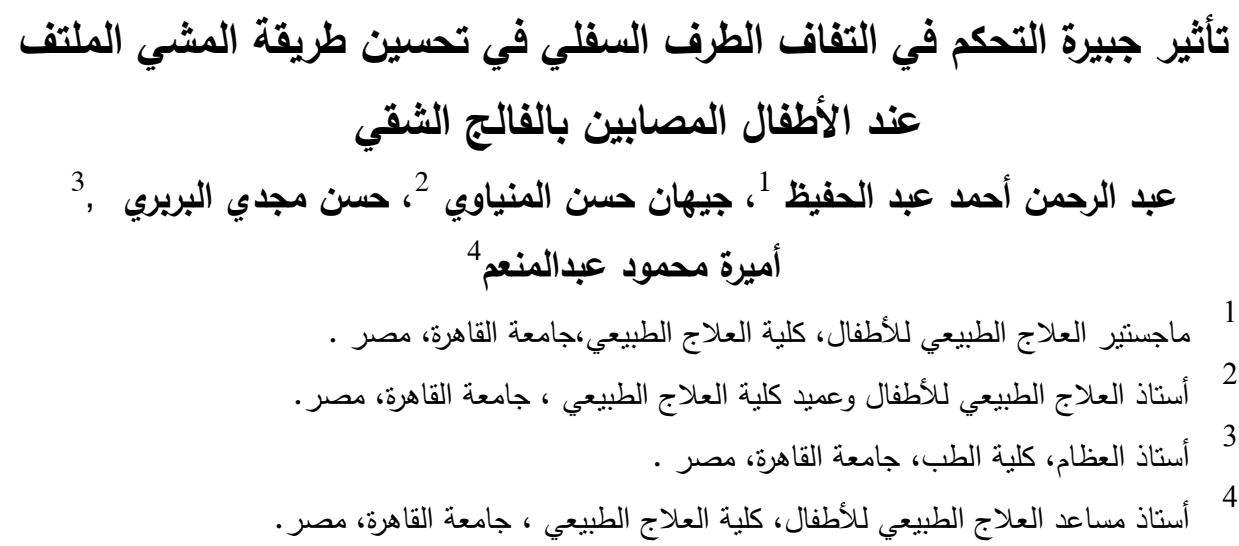

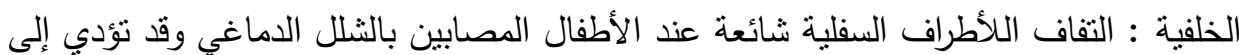
نمط مشية غير طبيعي .الأهداف: تأثثر جبيرة التحكم في التفاف الطرف التفاف السفلي في تحسين

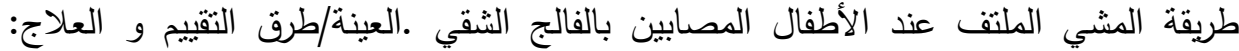

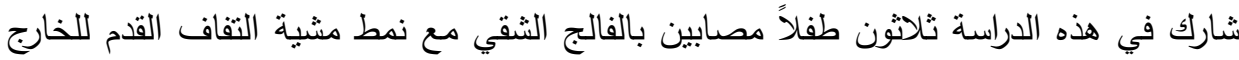
من كلا الجنسين تراوحت أعمارهم من 24 إلى 60 شهرًا. تم اختيارهم من مستشفى دمياط

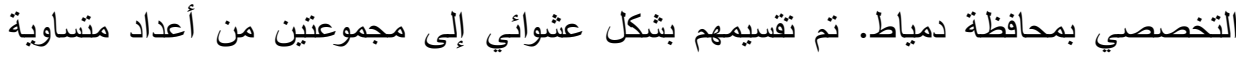

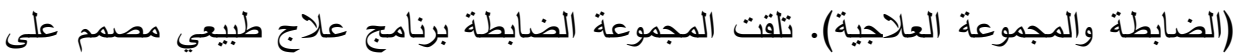
أساس نهج النمو العصبي لمدة 60 دقيقة بالإضافة إلى التدريب على المشي لفي لمدة 30 دقيقة بينما تلقت المجموعة العلاجية نفس البرنامج مع إرتداء جبيرة التحكم في التفاف التفاف الطرف الفئ السفلي

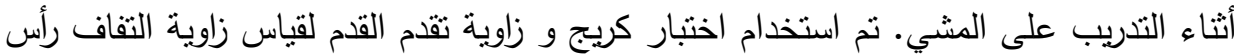


و رقبة عظمة الفخذ للأكام وزاوية التفاف القدم للخارج على التوالي. تم تقيبم كل طفل مرتين ،

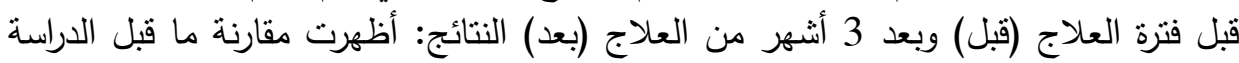

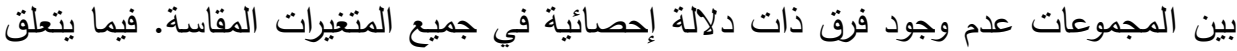

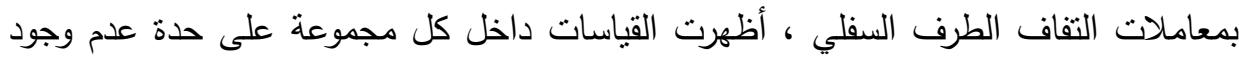

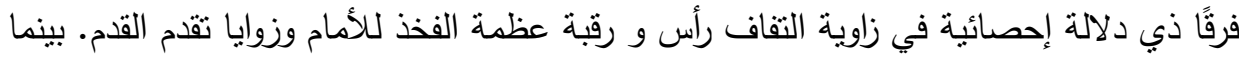
كان هناك تحسن كبير في عدد الخطوات وسرعة وطول الخطوة بينما نم تسجيل عدم وجود فرق فرق

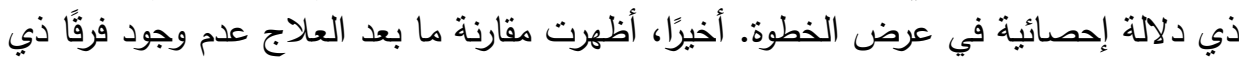

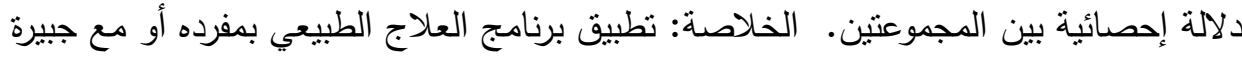

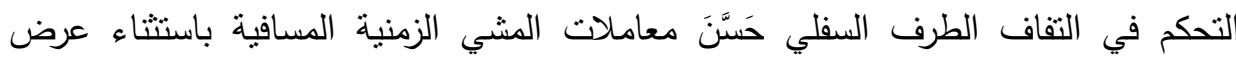
الخطوة، لكنه لم يحسن معاملات إلتفاف الطرف السفلي.

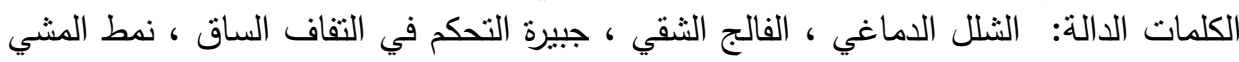

